\title{
Gas-phase reactions of carbon cluster ions with isomeric chloropropenes
}

\author{
Jing Sun ${ }^{\mathrm{a}}$, Hans-Friedrich Grützmacher*,a ${ }^{*}$ Chava Lifshitz \\ ${ }^{\mathrm{a}}$ Fakultät für Chemie der Universität Bielefeld, Postfach 100131, Universitätsstraße, Bielefeld, Germany \\ ${ }^{\mathrm{b}}$ Fritz Haber Research Center for Molecular Dynamics, Department of Physical Chemistry, The Hebrew University of Jerusalem, \\ Jerusalem 91904, Israel
}

Received 30 March 1994; accepted 19 May 1994

\begin{abstract}
Gas-phase ion/molecule reactions of carbon cluster ions $\left(\mathrm{C}_{n}^{++}, n=10-20\right)$ with allylchloride (AC) and 2-chloropropene (CP) were investigated by Fourier transform ion cyclotron resonance spectrometry (FT-ICR). The carbon cluster ions $\mathrm{C}_{n}^{++}$were generated by electron impact ionization of perchloroarenes and subsequent elimination of all $\mathrm{Cl}$ substituents from the molecular ion giving rise to monocyclic $\mathrm{C}_{n}^{+}$. Clear pseudo-first-order reactions were observed for the carbon cluster ions $\mathrm{C}_{n}^{-+}$thus formed without any sign of isomeric clusters of different reactivity. An exccption is $\mathrm{C}_{11}^{-+}$, for which a small amount of unreactive ions was observed. The reactions of $\mathrm{C}_{n}^{++}$with $\mathrm{AC}$ and $\mathrm{CP}$ at low operating pressure $\left(1.2 \times 10^{-8}-8.0 \times 10^{-7}\right.$ mbar $)$ yield product ions $\mathrm{C}_{n+3} \mathrm{H}_{5}^{+}$by loss of $\mathrm{Cl}$ from an intermediate adduct. Rate constants for the reactions with $\mathrm{CP}$ are always distinctly larger than with $\mathrm{AC}$ in spite of the smaller dissociation energy of the $\mathrm{C}-\mathrm{Cl}$ bond in $\mathrm{AC}$. Exceptionally large reaction efficiencies are found for $\mathrm{C}_{13}^{++}$and $\mathrm{C}_{17}^{++}$, corroborating the high reactivity of cyclic anti-aromatic $\mathrm{C}_{n}^{\cdot+}$ with $n=4 r+1$. The nature of the reaction products depends on the number of carbon atoms in $\mathrm{C}_{n}^{++}$. Secondary reactions of primary product ions $\mathrm{C}_{n+3} \mathrm{H}_{5}^{+}$were observed only for reactions of odd numbered $\mathrm{C}_{13}^{-+}$and $\mathrm{C}_{17}^{+}$. Further, on collision induced dissociation (CID) the product ions from even $\mathrm{C}_{n}^{-+}$yield exclusively $\mathrm{C}_{3} \mathrm{H}_{3}^{+}$, while product ions from odd $\mathrm{C}_{n}^{++}$generate several fragment ions by loss of $\mathrm{H}$ and of $\mathrm{C}_{(2-4)} \mathrm{H}_{2}$. A reaction model explaining these observations is proposed.
\end{abstract}

Keywords: FT-ICR spectrometry; Ion/molecule reaction; Carbon cluster ions; Rate constants; Chloropropene

\section{Introduction}

The structure and reactivity of the carbon cluster ions $\mathrm{C}_{n}^{++}$have attracted great interest during the last five years [1]. Experimental studies have shown that small $\mathrm{C}_{n}^{++}(n<10)$ cluster ions are more reactive than larger ones $[2,3]$ and also undergo different

\footnotetext{
* Corresponding author.
}

reactions. The ion/molecule reactions of small $\mathrm{C}_{n}^{+}$cluster ions are characterized by a typical carbene reactivity towards small saturated and unsaturated hydrocarbons [2a]. In the case of medium sized $\mathrm{C}_{n}^{+}(n=10-23)$ cluster ions only slow reactions are observed with these substrates. The different reactivity of $\mathrm{C}_{n}^{++}$towards neutral organic reactants is assigned to the different structures of small and medium sized $\mathrm{C}_{n}^{\cdot+}$. Both theoretical 
calculations [4] and experimental results $[2,4,5]$ indicate a change from linear to monocyclic structures of neutral and ionized $\mathrm{C}_{n}$ clusters occurring at $n=9$ or 10 . Thus, the carbenic end groups of the linear $\mathrm{C}_{n}^{\cdot+}$ are absent in the larger monocyclic $\mathrm{C}_{n}^{+}$causing the reduced reactivity of the latter ions. However, $\mathrm{C}_{n}^{+}(n=10-23)$ and benzene [6] as well as substituted benzenes and naphthalene [7] yield adduct ions with increased reaction efficiency which is attributed to the increased lifetime of the collision complexes with these large molecules [6].

Mono- and poly-cyclic $\mathrm{C}_{n}^{\cdot+}$ ions contain strained double or triple bonds and are expected to exhibit enhanced reactivity for cycloadditions. Recently, we have shown that the reactions of $\mathrm{C}_{n}^{++}(n=10-20)$ with acrylonitrile [8] and crotononitrile [9] yield adduct ions, very likely by radiative stabilization, analogous to the reaction with $\mathrm{HCN}$. However, for $n=10$ and 13 the rate constants of the reactions with these unsaturated nitriles are about 100 times larger than those with $\mathrm{HCN}$ [10]. In addition, not only $\mathrm{C}_{13}^{-+}$but also $\mathrm{C}_{17}^{+}$ shows a particularly large reactivity. These results demonstrate that medium sized monocyclic carbon cluster ions may exhibit a significant reactivity toward organic molecules
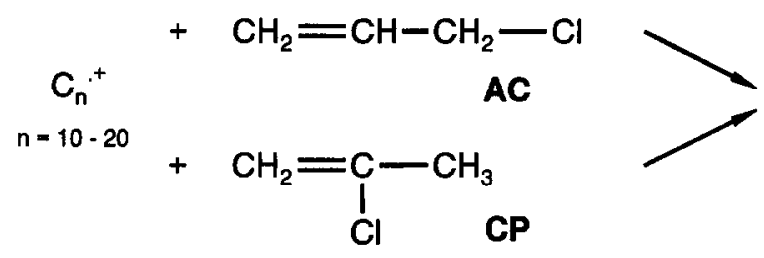

besides arenes. Furthermore, the reactivity of the monocyclic $\mathrm{C}_{n}^{\cdot+}$ ions appears to depend on their thermodynamic stability and electronic configuration. For example, the especially low ionization energies of $\mathrm{C}_{n}$ with $n=(4 r+3)$ have been explained by an aromatic $(4 r+2)$ configuration of the valence electrons of these cluster ions [11]. Accordingly, the $\mathrm{C}_{13}$ and $\mathrm{C}_{17}(n=4 r+1)$ cluster ions are anti-aromatic species which would explain their increased reactivity. In this paper, we report the ion/molecule reactions of $\mathrm{C}_{n}^{\cdot+}, n=10-20$, with allylchoride (AC) and 2-chloropropene (CP) (reaction 1) to explore further the reactivity of medium sized carbon cluster ions of monocyclic structure. It will be shown that $\mathrm{C}_{13}^{+}$and $\mathrm{C}_{17}^{+}$are again distinguished from their neighboring cluster ions by an increased reactivity paralleling the results obtained with the unsaturated nitriles. Contrary to these latter reactions no adduct ions are formed, but ions $\mathrm{C}_{n+3} \mathrm{H}_{5}^{+}$are formed exclusively by loss of $\mathrm{Cl}$ from the adducts. The loss of $\mathrm{H}$ from adduct ions was already observed as an additional reaction channel for the reactions with crotononitrile [9] and benzene [6], but only for odd numbered $\mathrm{C}_{n}^{+}$. However, in spite of the exclusive formation of $\mathrm{C}_{n+3} \mathrm{H}_{5}^{+}$from all $\mathrm{C}_{n}^{\cdot+}$ by reactions with $\mathrm{AC}$ and $\mathrm{CP}$, the nature of the product ions is clearly different for odd and even numbered $\mathrm{C}_{n}^{-+}$also in these cases. Thus, differences with respect to the type and structure of the products are obviously also typical for the ion/molecule reactions of monoclyclic carbon cluster ions.

$\mathrm{C}_{n+3} \mathrm{H}_{5}{ }^{+}+\mathrm{Cl} \cdot$

\section{Experimental}

The isomeric chloropropenes allylchloride (AC) and 2-chloropropene (CP) are available commercially (Merck, purity $>99 \%$ ) and were used without further purification. The carbon cluster ions studied were generated 
<smiles>ClC1=C(Cl)C(Cl)(Cl)c2c(Cl)c(Cl)c(Cl)c(Cl)c2C1(Cl)Cl</smiles>

1<smiles>Clc1c(Cl)c(Cl)c2c(c1Cl)-c1c(Cl)c(Cl)c(Cl)c(Cl)c1C(Cl)(Cl)C2(Cl)Cl</smiles>
5<smiles>Clc1c(Cl)c(Cl)c2c(c1Cl)-c1c(c(Cl)c3c(Cl)c(Cl)c(Cl)c(Cl)c3c1Cl)C2(Cl)Cl</smiles>

8<smiles>CC(C)(C)c1c(Cl)c(Cl)c2c(Cl)c(Cl)c(Cl)c(Cl)c2c1Cl</smiles>

2<smiles>Clc1c(Cl)c(Cl)c2c(c1Cl)-c1c(Cl)c(Cl)c(Cl)c3c(Cl)c(Cl)c(Cl)c(c13)C2(Cl)Cl</smiles>

6<smiles>Clc1c(Cl)c2c3c(c(Cl)c(Cl)c(Cl)c3c1Cl)C(Cl)(Cl)C2(Cl)Cl</smiles>

3<smiles></smiles>

7<smiles>Clc1c(Cl)c(Cl)c2c(c1Cl)c(Cl)c(Cl)c1c(Cl)c(Cl)c(Cl)c(Cl)c12</smiles>

9<smiles>Clc1c(Cl)c(Cl)c2c(c1Cl)-c1c(Cl)c(Cl)c(Cl)c(Cl)c1C2(Cl)Cl</smiles>

4<smiles></smiles>

10

Fig. 1. Perchloroarenes 1-10 used as precursor for $C_{n}^{\cdot+}$.

by electron impact ionization of the appropriatc pcrchlorinated aromatic compound (Fig. 1) and subsequent exhaustive chlorine elimination from the resulting molecular ions in the external ion source [12] of a Bruker CMS 47X FT-ICR spectrometer [13] equipped with a $4.7 \mathrm{~T}$ superconducting magnet.

The details of the preparation of the perchloroarenes 1-10 (Fig. 1), of the generation of the carbon cluster ions, and of the determination of the rate constants of their ion/molecule reactions have been described before [8]. Briefly, following the electron impact induced ionization $(70 \mathrm{eV})$ and fragmentation of the perchlorinated arenes in the external ion source, all ions were transferred into the FT-ICR cell, and the carbon cluster ions $\mathrm{C}_{n}^{\cdot+}$ were isolated according to their exact mass using high resolution resonance ejection techniques as described elsewhere [8]. Special care was taken to cool the isolated $\mathrm{C}_{n}^{\cdot+}$ to ambient temperature by admitting a pressure pulse of argon to the FT-ICR cell.

The ion/molecule reactions of more reactive $\mathrm{C}_{n}^{\cdot+}$ with the neutral chloropropenes were studied at a constant partial pressure of typically $1.2-5.0 \times 10^{-8}$ mbar, but a partial pressure up to $8.0 \times 10^{-7} \mathrm{mbar}$ had to be used for reactions of low efficiency. Transient signals were averaged for up to 100 experimental cycles prior to performing the Fourier transformation. The rate constants were determined by observing the decay of the 
Table 1

Product ions, rate constants, and reaction efficiencies of ion/molecule reactions of $\mathrm{C}_{n}^{++}$with allylchloride (AC) and 2-chloropropene (CP)

\begin{tabular}{|c|c|c|c|c|c|c|}
\hline \multirow[t]{2}{*}{$n$} & \multicolumn{3}{|c|}{ Neutral reagent $A C$} & \multicolumn{3}{|c|}{ Neutral reagent $C P$} \\
\hline & $\overline{\text { Products }}$ & $k_{\mathrm{b}_{1}}{ }^{\mathrm{a}}$ & Eff: $^{b}$ & Products & $k_{\mathrm{b}_{1}}^{\mathrm{a}}$ & Eff. $^{b}$ \\
\hline 10 & $\mathrm{C}_{13} \mathrm{H}_{5+}+\mathrm{Cl}^{\cdot}$ & 65 & 38.8 & $\mathrm{C}_{13} \mathrm{H}_{5}^{+}+\mathrm{Cl}^{-}$ & 150 & 94.8 \\
\hline 11 & $\begin{array}{l}\mathrm{C}_{14} \mathrm{H}_{5+}+\mathrm{Cl}^{\circ} \\
67 \% \\
\mathrm{C}_{11} \mathrm{Cl}^{+}+ \\
\mathrm{C}_{3} \mathrm{H}_{5} 33 \%\end{array}$ & 2.2 & 1.3 & $\begin{array}{l}\mathrm{C}_{14} \mathrm{H}_{5+}+\mathrm{Cl}^{\circ} \\
86 \% \\
\text { No reaction } \\
14 \%\end{array}$ & 60 & 39.4 \\
\hline 12 & $\mathrm{C}_{15} \mathrm{H}_{5+}+\mathrm{Cl}^{\cdot}$ & 61 & 36.9 & $\mathrm{C}_{15} \mathrm{H}_{5+}+\mathrm{Cl}^{\cdot}$ & 76 & 50.8 \\
\hline 13 & $\mathrm{C}_{16} \mathrm{H}_{5+}+\mathrm{Cl}^{\cdot}$ & 74 & 46.5 & $\mathrm{C}_{16} \mathrm{H}_{5+}+\mathrm{Cl}^{\cdot}$ & 120 & 81.0 \\
\hline 14 & $\mathrm{C}_{17} \mathrm{H}_{5+}+\mathrm{Cl}^{\cdot}$ & 33 & 21.0 & $\mathrm{C}_{17} \mathrm{H}_{5+}+\mathrm{Cl}^{*}$ & - & - \\
\hline 15 & $\mathrm{C}_{18} \mathrm{H}_{5+}+\mathrm{Cl}^{\cdot}$ & $<0.1$ & $<0.1$ & $\begin{array}{l}\mathrm{C}_{18} \mathrm{H}_{5+}+\mathrm{Cl}^{-} \\
3 \% \\
\mathrm{C}_{14} \mathrm{H}_{3}^{+}+\mathrm{C}_{4} \mathrm{H}_{2}+ \\
\mathrm{Cl} \\
50 \% \\
\mathrm{C}_{15} \mathrm{Cl}^{+}+\mathrm{C}_{3} \mathrm{H}_{5} \\
33 \% \\
\text { No reaction } \\
14 \%\end{array}$ & 16 & 11.1 \\
\hline 16 & $\mathrm{C}_{19} \mathrm{H}_{5+}+\mathrm{Cl}^{\cdot}$ & $<0.01$ & $<0.01$ & $\mathrm{C}_{19} \mathrm{II}_{5}^{+}+\mathrm{Cl}^{\cdot}$ & 5.5 & 3.8 \\
\hline 17 & $\mathrm{C}_{20} \mathrm{H}_{5+}+\mathrm{Cl}^{\cdot}$ & 5.8 & 4.4 & $\mathrm{C}_{20} \mathrm{H}_{5}^{+}+\mathrm{Cl}^{\cdot}$ & 46 & 32.0 \\
\hline 18 & No reaction & $<0.01$ & $<0.01$ & $\mathrm{C}_{21} \mathrm{H}_{5}^{+}+\mathrm{Cl}^{-}$ & 6.7 & 4.7 \\
\hline 20 & No reaction & $<0.01$ & $<0.01$ & No reaction & $<0.1$ & $<0.1$ \\
\hline
\end{tabular}

${ }^{a} \times 10^{-11}\left(\mathrm{~cm}^{3}\right.$ molecule $\left.{ }^{-1} \mathrm{~s}^{-1}\right)$.

${ }^{b}$ Reaction efficiency (percent).

intensity of the ions $\mathrm{C}_{n}^{+}$relative to the product ions as a function of the reaction time. With the exception of the very slow reactions the process was followed until about $80-90 \%$ of the respective $\mathrm{C}_{n}^{+}$had reacted. The bimolecular rate constants $k_{\mathrm{bi}}$ were calculated taking into account the partial pressure of the respective chloropropene. The ion gauge was calibrated as discussed previously [8]. The rate constants reported are accurate within $20 \%$. The branching ratio of primary reactions was calculated from the ratios of product ion intensities during the initial period of the reaction. For secondary reactions the branching ratio was obtained by using the relevant ion intensities of the reaction products at the end of the reaction. The maximal estimated uncertainty of the branching ratios thus obtained corresponds to $\pm 20 \%$.

The collision induced decomposition (CID) of the product ions $\mathrm{C}_{n+3} \mathrm{H}_{5}^{+}$was studied as described previously [8] by isolating the respective product ion using the ion ejection facilities of the FT-ICR mass spectrometer, admitting argon into the ICR cell, and accelerating the ions by irradiation with the appropriate cyclotron frequency until about $50 \%$ of the product ions were fragmented. 


\section{Results and discussion}

\subsection{Kinetics}

The rate constants, $k_{\mathrm{bi}}$, the reaction efficiencies, and the products of the primary ion/molecule reactions of $\mathrm{C}_{n}^{+}(n=10-20)$ with the isomeric chloropropenes $\mathrm{AC}$ and $\mathrm{CP}$ are given in Table 1 . As mentioned before, $k_{\mathrm{bi}}$ was determined from the decay of the signal of the respective $\mathrm{C}_{n}^{\cdot+}$ ion by taking into account the (corrected) partial pressure of the neutral reagent. By varying the pressure no indication for tcrmolecular rcactions was seen. As an example the experimental ion intensity curves are shown in Fig. 2 for the reactions of $\mathrm{C}_{12}^{-{ }^{+}}$ and $\mathrm{C}_{13}^{+}$with $\mathrm{AC}$. With the exception of the reaction of $\mathrm{C}_{11}^{+}$and $\mathrm{C}_{15}^{-+}$with $\mathrm{CP}$, a monoexponential decay of the $\mathrm{C}_{n}^{++}$signal was observed up to $90 \%$ completion of the reaction. For the reaction of $\mathrm{C}_{11}^{+}$and $\mathrm{C}_{15}^{+}$ with $\mathrm{CP}$, but not with $\mathrm{AC}$, about $14 \%$ of the cluster ions were unreactive. However, the reactions with $\mathrm{AC}$ are much slower and a small amount of unreactive cluster ions would have been difficult to detect. The clear pseudo-first-order kinetics obtained for all other reactions is very strong evidence that the rcactions of ions without excess of encrgy were studied and that the $\mathrm{C}_{n}^{++}$generated from

a)

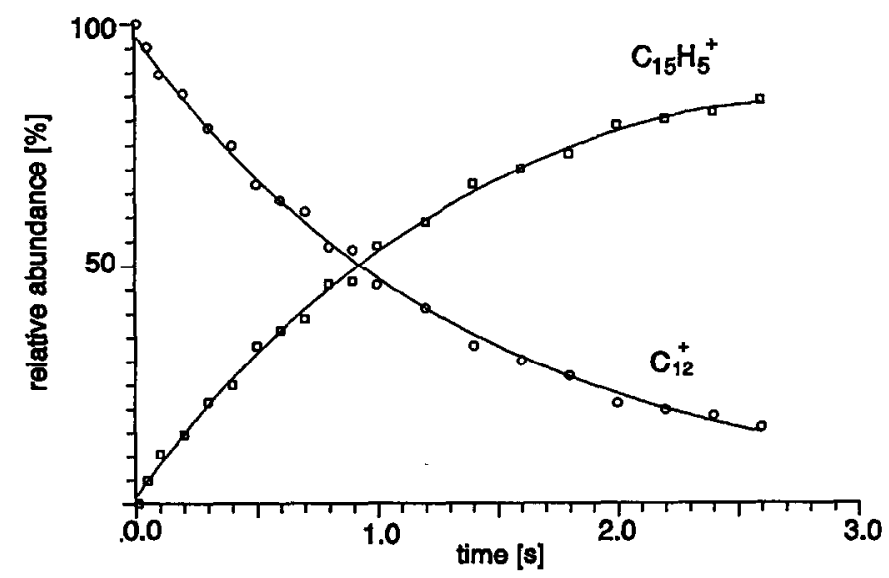

b)

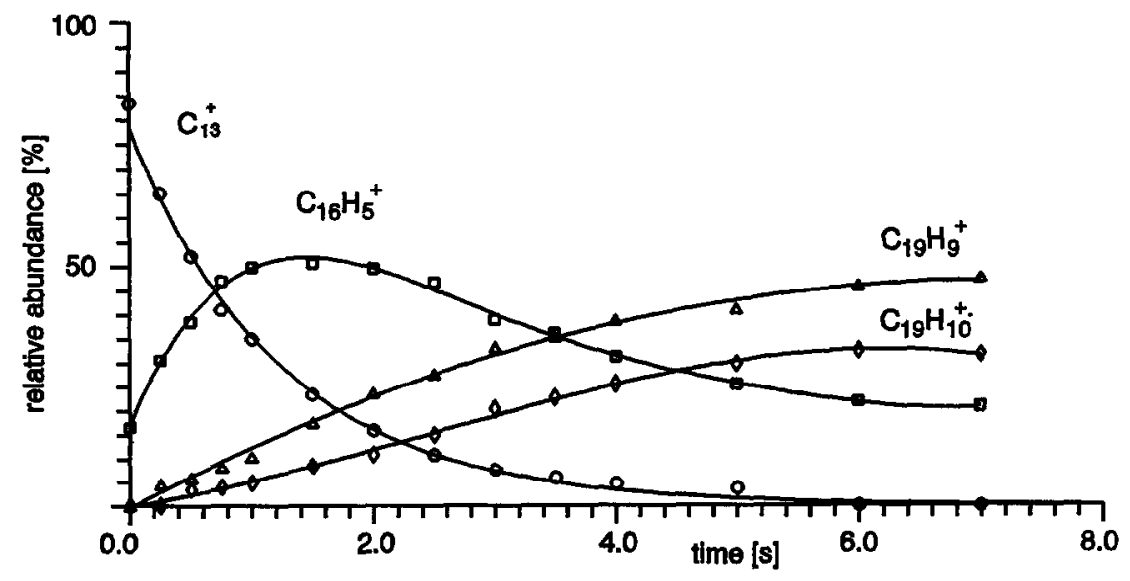

Fig. 2. Kinetic ion intensity curves for the reaction of $\mathrm{C}_{i 2}^{+}$(a) and $\mathrm{C}_{13}^{+}$(b) with $\mathrm{AC}$. 
the perchloroarenes are homogeneous in structure, because different reactivities are expected for isomeric $\mathrm{C}_{n}^{\cdot+}$. In view of the large excess of energy which has to be imparted to the arene molecular ions for exhaustive dechlorination, it is likely that rearrangements of the carbon skeleton occur and favor eventually the formation of $\mathrm{C}_{n}^{+}$in their most stable monocyclic structure. Recently, this has been experimentally proved for $\mathrm{C}_{12}^{\cdot+}$ generated by electron impact from decachloroacenaphthene 3 (Fig. 1) [14]. As has been discussed elsewhere [9], one mechanism to account for the transformation of a polycyclic perchloroarene into a monocyclic carbon cluster is a sequence of retroBergman cyclizations [15] depicted in Fig. 3 for the molecular ions of decachlorofluorene 4 for which the series of $\mathrm{Cl}$ eliminations for the molecular ion has been modelled by semiempirical AM1 calculations. As expected, the most stable $\mathrm{C}_{13} \mathrm{Cl}_{9}^{+}$fragment ion arises by<smiles>Clc1c(Cl)c(Cl)c2c(c1Cl)-c1c(Cl)c(Cl)c(Cl)c(Cl)c1C2(Cl)Cl</smiles>

4<smiles>Clc1c(Cl)c(Cl)c2c(c1Cl)-c1c(Cl)c(Cl)c(Cl)c(Cl)c1[C+]2Cl</smiles><smiles>CCc1c(Cl)c(Cl)c2c(c1Cl)-c1cc(Cl)c(Cl)c(Cl)c1[C+]2</smiles><smiles>ClC#CC#CC#CC#C[C+](Cl)C(Cl)=C(Cl)C#CC#CC(Cl)=C(Cl)Cl</smiles><smiles>CC</smiles>

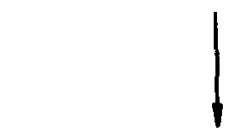<smiles>ClC1=C(Cl)[C+](Cl)C#CCc2c(Cl)c(Cl)c(Cl)c(Cl)c2C#C1</smiles>
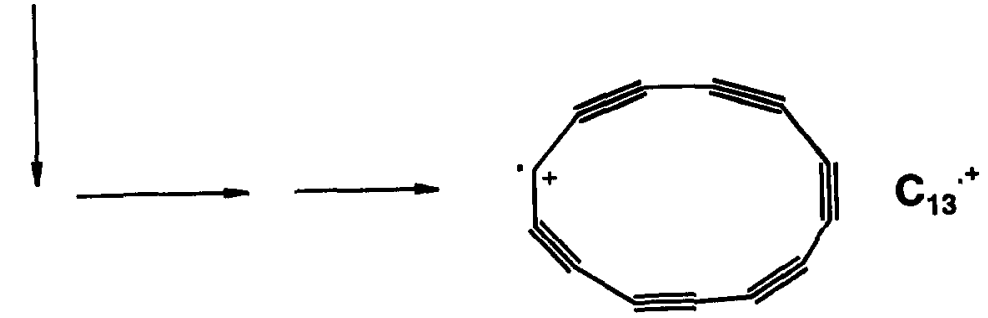

Fig. 3. Electron impact induced formation of monocyclic $\mathrm{C}_{13}^{\cdot+}$ from decachlorophenanthrene radical cations 4 (schematic presentation of AM1 low energy path way). 
loss of $\mathrm{Cl}$ from position 9. The subsequent energetically most favorable losses of two further $\mathrm{Cl}$ substituents occur from positions 4 and 9. Interestingly, according to AM1, the resulting $\mathrm{C}_{13} \mathrm{Cl}_{7}^{+}$ion with a fluorene structure is not a minimum on the potential energy surface but ring opens without a barrier to the $\mathrm{C}_{13} \mathrm{Cl}_{7}^{+}$ion with the structure of a benz[9]annulene. A second retro-Bergman cyclization yielding a monocyclic[13]annulene ion $\mathrm{C}_{13} \mathrm{Cl}_{5}^{+}$occurs during the further elimination of two $\mathrm{Cl}$ substituents from positions 5 and 8 , and eventually the losses of the remaining $\mathrm{Cl}$ substituents result in the monocyclic $\mathrm{C}_{13}^{-+}$. However, it is obvious that the other types of skeletal rearrangements also have to occur, particularly for the larger polycyclic perchloroarene molecular ions, to arrive at a monocyclic structure for the $\mathrm{C}_{n}^{+}$. Thus, additional experiments are under way to establish the route of carbon cluster ion formation by electron impact induced dechlorination of perchloroarenes.

The values of $k_{\mathrm{bi}}$ for the reactions of $\mathrm{C}_{10}^{\cdot+}$, $\mathrm{C}_{12}^{+}, \mathrm{C}_{13}^{\cdot+}$, and $\mathrm{C}_{14}^{-+}$with $\mathrm{AC}$ and $\mathrm{CP}$ are large, but $\mathrm{C}_{11}^{-+}$exhibits a noticeable reactivity only toward CP. For the cluster ions with more than 14 carbon atoms only $\mathrm{C}_{17}^{+}$reacts fast enough with $\mathrm{AC}$ to allow a determination of $k_{\mathrm{bi}}$. Fore the other $\mathrm{C}_{n}^{\cdot+}$ ions the reaction rates with $\mathrm{AC}$ were so slow, even at high partial pressures of $\mathrm{AC}$, that only upper limits can be given for $k_{\mathrm{bi}}$. In the case of CP, again only $\mathrm{C}_{17}^{++}$reacts rapidly for the larger $\mathrm{C}_{n}^{\cdot+}$. The efficiencies for the reactions both with $\mathrm{AC}$ and $\mathrm{CP}$ exhibit a clear dependence on the size of the carbon cluster ion and are especially large for $\mathrm{C}_{13}^{\cdot+}$ and $\mathrm{C}_{17}^{\cdot+}$ compared to their neighbors. An analogous dependence of reactivity on cluster size has been observed for the reactions of $\mathrm{C}_{n}^{\cdot+}$ with acrylonitrile [8], crotononitrile [9], and benzene [6]. In the latter case Dunbar and Pozniak were able to extend this series of cluster ions with $(4 r+1)$ carbon atoms and enhanced reactivity to $\mathrm{C}_{21}^{+}$.
Obviously, this $(4 r+1)$ modulation of the reactivity of monocyclic $\mathrm{C}_{n}^{-+}$is a general phenomenon. A related series of carbon clusters, but this time with $(4 r+3)$ carbon atoms, was observed by Bach and Eyler [11] to exhibit an especially low ionization energy (IE). These authors explained their observation by formation of an aromatic $\pi$-electron system upon ionization of the monocyclic clusters $\mathrm{C}_{(4 r+3)}$ $(r=2,3,4,5)$. Following this argument, we may postulate that the cluster ions $\mathrm{C}_{(4 r+1)}$ $(r=3,4,5)$ contain an anti aromatic $\pi$-electron system, and this would explain the increased reactivity of these ions. Then one expects a decreased reactivity for the aromatic ions $\mathrm{C}_{11}^{+}$and $\mathrm{C}_{15}^{+}$, but this is only corroborated for $\mathrm{C}_{11}^{+}$because of the generally low reactivity of the large ions in this series.

\subsection{Chemoselectivity}

Interestingly, all reactive cluster ions $\mathrm{C}_{n}^{\cdot+}$ with $n=10-20$ show a considerable chemoselectivity between the isomeric chloropropenes, since the efficiency of the reaction with $\mathrm{CP}$ always exceeds that with AC. This is more distinct for the less reactive $\mathrm{C}_{n}{ }^{+}$ ion in line with the general rule that an inverse relationship exists between chemical reactivity and selectivity [16]. Thus, $\mathrm{C}_{13}^{+}$reacts about two times faster with $\mathrm{CP}$ than with $\mathrm{AC}$, while for $\mathrm{C}_{17}^{+} \mathrm{a}$ factor of five and for the less reactive "aromatic" $\mathrm{C}_{11}^{+}$and $\mathrm{C}_{15}^{+}$a factor of 30 and $>100$, respectively, is observed. A similar systematic difference in $\mathrm{C}_{n}^{+}$reactivity was observed for the reactions with acrylonitrile and crotononitrile in favour of the latter reagent [9]. This was not attributed to the increased number of degrees of freedom of crotononitrile which increase the lifetime of the collision complex, but to the lower IE of crotononitrile (10.22 eV [17]) compared to acrylonitrile (10.91 eV [17]). In the case of the isomeric chloropropenes, different degrees of freedom are definitely not the origin for the 
higher reactivity of the $\mathrm{C}_{n}^{\cdot+}$ ion towards CP. The IE of AC is $10.05 \mathrm{eV}$ [17], but the IE of CP is not known. Assuming the same IE difference of $0.38 \mathrm{eV}$ as in the case of the corresponding bromopropenes [17], CP has an IE around 9.7 $\mathrm{eV}$. Thus, the higher reactivity of the $\mathrm{C}_{n}^{\cdot+}$ ion observed for CP is very likely a further example of a general rule that monocyclic $\mathrm{C}_{n}^{+}$ions prefer reactions with neutral substrates of low IE.

\subsection{Product ions}

With the exception of the reactions of $\mathrm{C}_{11}{ }^{+}$ with $\mathrm{AC}$ and of $\mathrm{C}_{15}^{+}$with $\mathrm{CP}$ the only primary product ions for the reactions of $\mathrm{C}_{n}{ }^{+}$with $\mathrm{AC}$ and $\mathrm{CP}$ are the ions $\mathrm{C}_{n+3} \mathrm{H}_{5}^{+}$formed by loss of $\mathrm{Cl}$ from the collision complex (Table 1). $\mathrm{C}_{11}^{+}$ and $\mathrm{C}_{15}{ }^{+}$yield additionally a minor product by retaining $\mathrm{Cl}$ and losing $\mathrm{C}_{3} \mathrm{H}_{5}$ from the collision complex in some of the reactions. $\mathrm{C}_{15}^{+}$also forms product ions $\mathrm{C}_{14} \mathrm{H}_{3}^{+}$, obviously by loss of a $\mathrm{C}_{4} \mathrm{H}_{2}$ fragment from an intermediate ion $\mathrm{C}_{18} \mathrm{H}_{5}^{+}$which is detected only with $3 \%$ of total reaction products. The loss of $\mathrm{C}_{4} \mathrm{H}_{2}$ is also observed from the product ions $\mathrm{C}_{n+3} \mathrm{H}_{5}^{+}$of $\mathrm{C}_{10}^{\cdot+}$, but only by CID (see below). However, the rate constants of the ion/molecule reactions of $\mathrm{C}_{11}^{+}$and $\mathrm{C}_{15}^{+}$are small, in particular with $\mathrm{AC}$, and this as well as the unique course of the reactions may reflect a special stability of these cluster ions.

The formation of $\mathrm{C}_{n+3} \mathrm{H}_{5}^{+}$product ions corresponds formally to a substitution of the $\mathrm{Cl}$ in the neutral reagent. Both cleavage is expected to be much easier for the weak allylic $\mathrm{C}-\mathrm{Cl}$ bond $\left(D(\mathrm{C}-\mathrm{Cl}) \approx 293 \mathrm{~kJ} \mathrm{~mol}^{-1}\right)$ of $\mathrm{AC}$ than for the strong vinylic $\mathrm{C}-\mathrm{Cl}$ bond $\left(D(\mathrm{C}-\mathrm{Cl}) \approx 366 \mathrm{~kJ} \mathrm{~mol}^{-1}\right)$ of $\mathrm{CP}$. This is not observed experimentally, however, since under identical conditions $\mathrm{CP}$ always reacts distinctly faster with the $\mathrm{C}_{n}^{+}$than $\mathrm{AC}$ does. This proves unambiguously that the formation of the $\mathrm{C}_{n+3} \mathrm{H}_{5}^{+}$product ions corresponds not to a direct substitution reaction at the carbon-chlorine bond of the neutral chloropropenes but to a multi-step process with the rate determining step preceding the cleavage of the $\mathrm{C}-\mathrm{Cl}$ bond. These preceding steps include addition of $\mathrm{C}_{n}^{+}$to the double bond of the chloropropene and very likely hydrogen rearrangements.

In addition to the $(4 r+1)$ modulation of the reaction efficiency of monocyclic $\mathrm{C}_{n}^{\cdot+}$ with cluster size, an alternation of the nature of the reaction products was observed in the reaction of odd and even numbered $\mathrm{C}_{n}^{\cdot+}$ with acrylonitrile [8], crotononitrile [9], and benzene [6]. Consistently $\mathrm{C}_{n}^{+}$ions with an odd number of carbon atoms yield only adduct ions, while additionally loss of $\mathrm{H}$ and subsequently secondary reactions were found for even numbered $\mathrm{C}_{n+}^{+}$. The reactions of $\mathrm{C}_{n}^{+}$ with the chloropropenes are examples in which formally the same product ions are formed irrespective of an odd or even number of carbon atoms in the cluster ion. However, the $\mathrm{C}_{\mathrm{n}+3} \mathrm{H}_{5}^{+}$product ions formed are clearly and systematically different for odd and even numbered carbon cluster ions. Thus, as is seen in Fig. 2 for $\mathrm{C}_{12}^{+}$and $\mathrm{C}_{13}^{+}$, the $\mathrm{C}_{n+3} \mathrm{H}_{5}^{+}$ions generated from even numbered $\mathrm{C}_{n}^{+}$and $\mathrm{AC}$ or $C P$ are unreactive towards the respective chloropropene. In contrast, the primary product ions of odd numbered $\mathrm{C}_{13}{ }^{+}$or $\mathrm{C}_{17}^{+}$ reacting with $\mathrm{AC}$ and $\mathrm{CP}$ undergo secondary reactions by addition of a second molecule of the neutral reagent present followed by elimination of $\mathrm{HCl}$ and $\mathrm{Cl}$, respectively (Table 2). Therefore, the reactions of $\mathrm{C}_{n}^{+}$with $\mathrm{AC}$ and $\mathrm{CP}$ also fit to the rule that odd and even numbered monocyclic $\mathrm{C}_{n}^{\cdot+}$ typically yield different products with organic reagents. In the case of the chloropropenes, product ions of a systematically different reactivity are formed.

The alternation of the type and structure of the reaction products is related to the different organization of the $\pi$-electrons in odd and even numbered unsaturated carbon rings. 
Table 2

Product ions and branching ratio of secondary reactions of $\mathrm{C}_{n}^{+}$with allylchloride $(\mathrm{AC})$ and 2-chloropropene (CP)

\begin{tabular}{|c|c|c|c|c|c|}
\hline \multirow[t]{2}{*}{$n$} & \multirow{2}{*}{$\begin{array}{l}\text { Primary } \\
\text { product } \\
\text { ion }\end{array}$} & \multicolumn{4}{|c|}{ Secondary products } \\
\hline & & $\overline{\text { With AC }}$ & $\begin{array}{l}\text { Branching } \\
\text { ratio }\end{array}$ & With CP & $\begin{array}{l}\text { Branching } \\
\text { ratio }\end{array}$ \\
\hline 13 & $\mathrm{C}_{16} \mathrm{H}_{5}^{+}$ & $\begin{array}{l}\text { No reaction } \\
\mathrm{C}_{19} \mathrm{H}_{5}^{+}+\mathrm{Cl}^{\text {. }} \\
\mathrm{C}_{19} \mathrm{H}_{4}^{+}+\mathrm{HCl}\end{array}$ & $\begin{array}{l}22 \% \\
31 \% \\
47 \%\end{array}$ & $\begin{array}{l}\text { No reaction } \\
\mathrm{C}_{19} \mathrm{H}_{5}^{+}+\mathrm{Cl}^{-} \\
\mathrm{C}_{19} \mathrm{H}_{4}^{+}+\mathrm{HCl}\end{array}$ & $\begin{array}{l}50 \% \\
35 \% \\
15 \%\end{array}$ \\
\hline 17 & $\mathrm{C}_{20} \mathrm{H}_{5}^{+}$ & $\begin{array}{l}\text { No reaction } \\
\mathrm{C}_{23} \mathrm{H}_{10}^{+}+\mathrm{Cl}^{-} \\
\mathrm{C}_{23} \mathrm{H}_{9}^{+}+\mathrm{HCl}\end{array}$ & $\begin{array}{l}15 \% \\
54 \% \\
31 \%\end{array}$ & $\begin{array}{l}\text { No reaction } \\
\mathrm{C}_{23} \mathrm{H}_{10}^{+}+\mathrm{Cl}^{+} \\
\quad-\end{array}$ & $\begin{array}{l}35 \% \\
65 \% \\
-\end{array}$ \\
\hline
\end{tabular}

The monocyclic $\mathrm{C}_{n}^{+}$contain two orthogonal delocalized electron systems. The first one corresponds to the delocalized $\pi$-MO system of an annulene, while the second one has electron delocalization in the plane of the ring as is known for arynes and other dehydroannulenes. As shown in Fig. 4, valence bond structures corresponding to a cyclic polyacetylene are only possible for even numbered rings, while odd numbered rings with triple bonds leave a carbene-like $\mathrm{C}$ atom. For the even numbered ring one expects the electronic structure of a
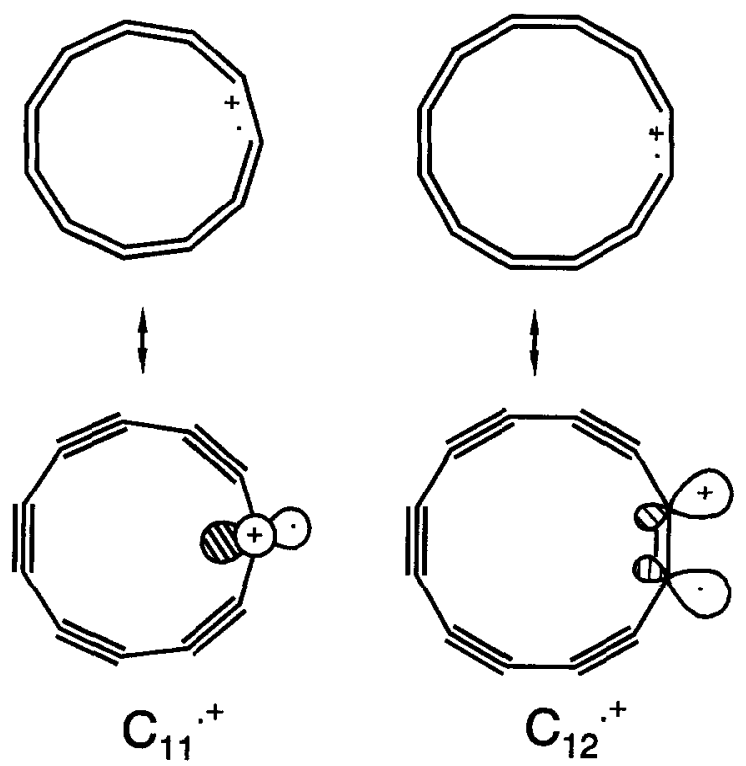

Fig. 4. Mesomeric valence bond structures of monocyclic $\mathrm{C}_{13}^{\cdot+}$ and $\mathrm{C}_{14}^{\cdot+}$. "conventional" organic molecular ion with the positive charge and the radical electron in the same delocalized MO. However, in the case of odd numbered $\mathrm{C}_{n}^{\cdot+}$ the positive charge and the radical electron are likely to reside in separate orthogonal MO typical of distonic ions [18]. Conceivably, the ion/ molecule reactions of these two types of carbon radical cations should be different [19]. The exact electronic configurations of monocyclic $\mathrm{C}_{n}^{\cdot+}$ ions have to be substantiated by high level ab-initio calculations and preferably by high resolution spectroscopy of carbon cluster ions. Nevertheless, the systematically different reaction products observed for odd and even numbered carbon cluster radical cations support this suggestion. In this connection it is significant that secondary reactions by addition of a second molecule of the respective chloropropene are only observed for the anti aromatic cluster ions $\mathrm{C}_{13}^{+}$and $\mathrm{C}_{17}^{+}$but not for the aromatic cluster ions $\mathrm{C}_{11}^{+}$and $\mathrm{C}_{15}^{++}$. Very likely the positive charge of the aromatic cluster radical cations is fully delocalized as in the tropylium ion and the reactions are initiated by the radical site. Therefore, the loss of $\mathrm{Cl}^{-}$from the adduct with $\mathrm{AC}$ or $\mathrm{CP}$ leaves an even electron cation unreactive in further addition reactions. A radical reaction is also indicated by the unique $\mathrm{Cl}$ abstraction of these aromatic $\mathrm{C}_{n}^{-+}$ions from the chloropropenes. 
Table 3

Collision induced decomposition (CID) of product ions $\mathrm{C}_{n+3} \mathrm{H}_{5}^{+}$

\begin{tabular}{|c|c|c|c|c|c|}
\hline \multirow[t]{2}{*}{$n$} & \multirow{2}{*}{$\begin{array}{l}\text { Primary } \\
\text { product } \\
\text { ion }\end{array}$} & \multicolumn{2}{|l|}{ With AC } & \multicolumn{2}{|l|}{ With CP } \\
\hline & & CID fragments ${ }^{a}$ & Rel int. ${ }^{b}$ & CID fragments $^{\mathrm{a}}$ & Rel. int. $^{b}$ \\
\hline 10 & $\mathrm{C}_{13} \mathrm{H}_{5}^{+}$ & $\begin{array}{l}\mathrm{C}_{3} \mathrm{H}_{3}^{+}+\mathrm{C}_{10} \mathrm{H}_{2} \\
\mathrm{C}_{9} \mathrm{H}_{3}^{+}+\mathrm{C}_{4} \mathrm{H}_{2} \\
\mathrm{C}_{11} \mathrm{H}_{3}^{+}+\mathrm{C}_{2} \mathrm{H}_{2}\end{array}$ & $\begin{array}{l}20 \\
45 \\
35\end{array}$ & $\begin{array}{l}\mathrm{C}_{3} \mathrm{H}_{3}^{+}+\mathrm{C}_{10} \mathrm{H}_{2} \\
\mathrm{C}_{9} \mathrm{H}_{3}^{+}+\mathrm{C}_{4} \mathrm{H}_{2} \\
\mathrm{C}_{11} \mathrm{H}_{3}^{+}+\mathrm{C}_{2} \mathrm{H}_{2}\end{array}$ & $\begin{array}{l}18 \\
35 \\
47\end{array}$ \\
\hline 12 & $\mathrm{C}_{15} \mathrm{H}_{5}^{+}$ & $\mathrm{C}_{3} \mathrm{H}_{3}^{+}+\mathrm{C}_{12} \mathrm{H}_{2}$ & 100 & $\mathrm{C}_{3} \mathrm{H}_{3}^{+}+\mathrm{C}_{12} \mathrm{H}_{2}$ & 100 \\
\hline 13 & $\mathrm{C}_{16} \mathrm{H}_{5}^{+}$ & $\begin{array}{l}\mathrm{C}_{16} \mathrm{H}_{4}^{+}+\mathrm{H}^{\cdot} \\
\mathrm{C}_{12} \mathrm{H}_{3}^{+}+\mathrm{C}_{2} \mathrm{H}_{2}\end{array}$ & $\begin{array}{l}51 \\
49\end{array}$ & $\mathrm{C}_{16} \mathrm{H}_{3}^{+}+\mathrm{H}_{2}$ & 100 \\
\hline 14 & $\mathrm{C}_{17} \mathrm{H}_{5}^{+}$ & $\mathrm{C}_{3} \mathrm{H}_{3}^{+}+\mathrm{C}_{14} \mathrm{H}_{2}$ & 100 & - & - \\
\hline 17 & $\mathrm{C}_{20} \mathrm{H}_{5}^{+}$ & $\mathrm{C}_{20} \mathrm{H}_{3}^{+}+\mathrm{H}_{2}$ & 100 & - & - \\
\hline
\end{tabular}

${ }^{a}$ Sum of neutral fragments.

${ }^{b}$ In percentage of total fragment ion intensity.

It is difficult to get conclusive information about the structures of the product ions by means of mass spectrometric techniques. So far as the intensity of the $\mathrm{C}_{n+3} \mathrm{H}_{5}^{+}$product ions allowed a CID study, the results confirm different types of product ions for odd and even numbered $\mathrm{C}_{n}^{+}$(Table 3). In no case did CID of the product ions regenerate the original $\mathrm{C}_{n}^{-+}$or lead to $\mathrm{C}_{3} \mathrm{H}_{5}^{+}$ions. This suggests that the $\mathrm{C}_{3} \mathrm{H}_{5}$ unit attached to $\mathrm{C}_{n}^{\cdot+}$ during the reaction with the chloropropenes is very likely not present as an intact entity in the $\mathrm{C}_{n+3} \mathrm{H}_{5}^{+}$product ions but that hydrogen migrations precede the loss of $\mathrm{Cl}$ from an intermediate addition product. The ions $\mathrm{C}_{15} \mathrm{H}_{5}^{+}$and $\mathrm{C}_{17} \mathrm{H}_{5}^{+}$generated from the even numbered $\mathrm{C}_{12}^{++}$and $\mathrm{C}_{14}^{++}$with $\mathrm{AC}$ and $\mathrm{CP}$ yield exclusively the stable $\mathrm{C}_{3} \mathrm{H}_{3}^{+}$fragment ion on CID. $\mathrm{C}_{3} \mathrm{H}_{3}^{+}$is also a product of CID of the $\mathrm{C}_{13} \mathrm{H}_{5}^{+}$ions from $\mathrm{C}_{10}^{+}$but in this case additional fragment ions are observed. However, the CA mass spectra of the product ions $\mathrm{C}_{n+3} \mathrm{H}_{5}^{+}$ions from the odd numbered $\mathrm{C}_{n}^{\cdot+}$ never exhibit a peak for $\mathrm{C}_{3} \mathrm{H}_{5}^{+}$ion but they do show signals due to loss of $\mathrm{H}$, $\mathrm{H}_{2}$, and $\mathrm{C}_{4} \mathrm{H}_{2}$, respectively, depending on the carbon cluster ion and the respective isomer of chloropropene. In the three cases in which CA mass spectra could be obtained for particular product ions formed with $\mathrm{AC}$ and CP, two CA spectra are different (Table 3). The CA spectra of $\mathrm{C}_{13} \mathrm{H}_{5}^{+}$product ions of $\mathrm{C}_{10}^{+}$exhibit only different relative abundances of identical fragment ions, but the $\mathrm{CA}$ mass spectra of the product ions $\mathrm{C}_{16} \mathrm{H}_{5}^{+}$of $\mathrm{C}_{13}^{+}$differ also with respect to the fragment ions formed. This indicates the formation of isomeric $\mathrm{C}_{n+3} \mathrm{H}_{5}^{+}$product ions by reaction of $\mathrm{C}_{n}^{-+}$with $\mathrm{AC}$ and $\mathrm{CP}$, respectively. This can also be concluded from the secondary reactions of $\mathrm{C}_{n+3} \mathrm{H}_{5}^{+}$ product ions generated from $\mathrm{C}_{13}^{+}$and $\mathrm{C}_{17}^{+}$ (Table 2). The ion intensity curves for the secondary reactions indicate that only a fraction of the product ions reacts in a secondary process with $\mathrm{AC}$ or $\mathrm{CP}$. This fraction of reactive product ions $\mathrm{C}_{n+3} \mathrm{H}_{5}^{+}$is different when formed from $\mathrm{AC}$ or $\mathrm{CP}$. Obviously, not only isomeric product ions are formed by reaction of a particular $\mathrm{C}_{n}^{\cdot+}$ ion with $\mathrm{AC}$ and $\mathrm{CP}$, respectively, but even the product ions generated with one of the chloropropenes are mixtures of isomers. Again, this is most easily explained in terms of an isomerization of the product ions by hydrogen migrations. 
even numbered $C_{n}{ }^{*}\left(C_{10}{ }^{+}\right)$:

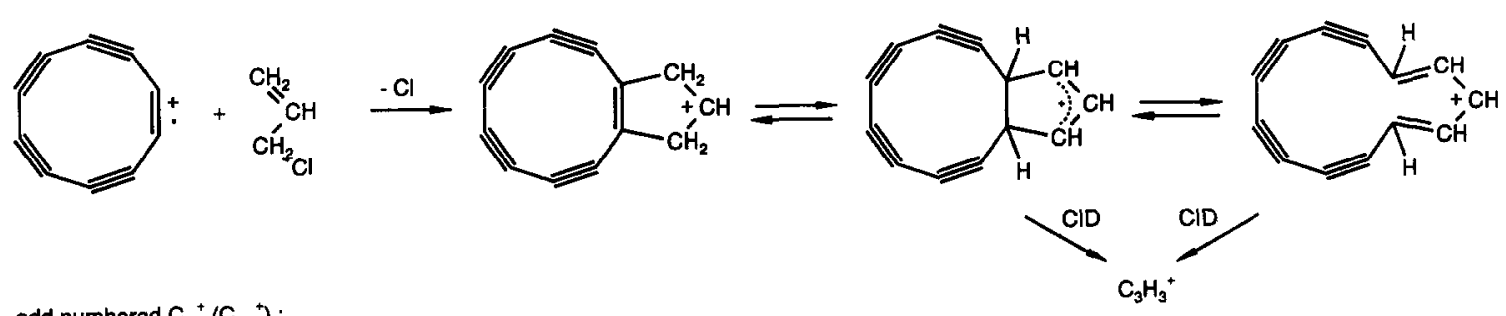

odd numbered $C_{n}{ }^{+}\left(C_{11}{ }^{+}\right)$:

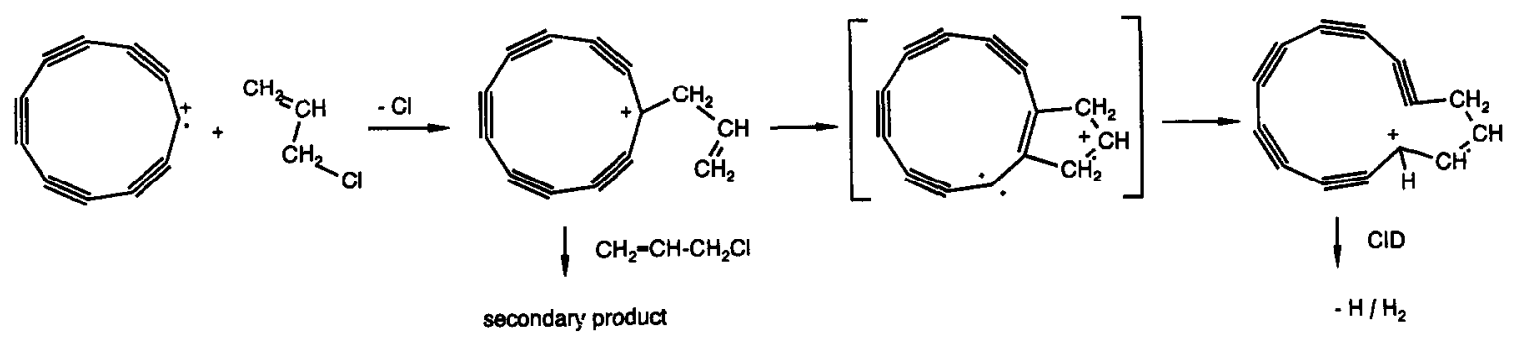

Fig. 5. Tentative reaction mechanism for reaction of even and odd $\mathrm{C}_{n}^{\cdot+}$ with $\mathrm{AC}$.

\subsection{Reaction mechanism}

The formation of mixtures of isomeric product ions makes it difficult to arrive at a definite mechanism for the ion/molecule reactions between the monocylic $\mathrm{C}_{n}^{\cdot+}$ ion and the neutral chloropropenes. A tentative reaction mechanism which is in accord with the experimental observations is shown in Fig. 5. It is suggested that the reaction of even numbered $\mathrm{C}_{n}^{+}$results eventually in a $[3+2]$ cycloaddition of the allyl group to the polyacetylenic ring of the cluster radical cation. This is followed by hydrogen shifts to generate a bicyclic derivative of a cyclopentenyl cation or a macrocyclic ion with delocalized positive charge. This ring enlargement may be assisted by release of steric strain. The delocalization ions are not expected to react further with a neutral chloropropene but can decompose easily to $\mathrm{C}_{3} \mathrm{H}_{3}^{+}$on CID. In the case of odd numbered $\mathrm{C}_{n}^{+}$a $[3+2]$ cycloaddition of a $\mathrm{C}_{3} \mathrm{H}_{5}$ radical does not result in a stable delocalization carbenium ion and the special electronic situation can induce more easily a ring enlargement to a now even membered ring and/or more excessive hydrogen migrations. This is in accord with the formation of reactive isomers of the product ions and the CID induced loss of $\mathrm{H}$.

\section{Conclusion}

The results of this study of the reactions of the monocyclic $\mathrm{C}_{n}^{\cdot+}(n=10-20)$ ions with the two isomeric chloropropenes $\mathrm{AC}$ and $C P$ give additional insight into the reactivity of these cluster ions. Contrary to previous studies, no adduct ions are detected, but for all monocyclic $\mathrm{C}_{n}^{\cdot+}$ only product ions $\mathrm{C}_{n+3} \mathrm{H}_{5}^{+}$are formed by loss of $\mathrm{Cl}$ from intermediate adducts with $\mathrm{AC}$ and $\mathrm{CP}$. In spite of this different course of the reactions, the dependence of the reaction efficiency on cluster size exhibits the same $(4 r+1)$ modulation observed before for the reactions of $\mathrm{C}_{n}^{+}$with unsaturated nitriles [8,9] and arenes [6,7]. Certainly, this effect is due to some property of the monocyclic $\mathrm{C}_{n}^{+}$ion and very likely due to the anti-aromatic character of 
cluster radical cations with $(4 r+1)$ carbon atoms. It was not possible to detect generally an especially small reactivity for the aromatic series of $\mathrm{C}_{n}^{\cdot+}$ with $n=(4 r+3)$ because of the low reactivity of the larger $\mathrm{C}_{n}^{\cdot+}$, but $\mathrm{C}_{11}^{\cdot+}$ is less reactive towards $\mathrm{AC}$ and $\mathrm{CP}$ than the neighboring cluster ions and yields $\mathrm{C}_{n+3} \mathrm{H}_{5}^{+}$product ions not reactive in secondary reactions. Similarly, no secondary condensation reactions were observed for the other aromatic cluster ions $\mathrm{C}_{15}^{+}$.

The products of the ion/molecule reactions of odd and even numbered $\mathrm{C}_{n}^{\cdot+}$ with unsaturated nitriles [8,9] and with arenes [6] are systematically different. In the case of the chloropropenes the odd/even alternation of the reactions of $\mathrm{C}_{n}^{-+}$is not reflected in the type of product ions formed but in the structure and reactivity of the $\mathrm{C}_{n+3} \mathrm{H}_{5}^{+}$product ions. Thus, only the product ions derived from even numbered $\mathrm{C}_{n}^{++}$yield $\mathrm{C}_{3} \mathrm{H}_{3}^{+}$by $\mathrm{CID}$, while product ions of odd numbered $\mathrm{C}_{n}^{\cdot+}$ typically lose $\mathrm{H}$ or $\mathrm{H}_{2}$ besides larger fragments. Further, only the $\mathrm{C}_{n+3} \mathrm{H}_{5}^{+}$from $\mathrm{C}_{13}^{+}$and $\mathrm{C}_{17}^{++}$undergo secondary reactions with $\mathrm{AC}$ and $\mathrm{CP}$, although a varying fraction of these product ions is also unreactive. Obviously, the $\mathrm{C}_{n+3} \mathrm{H}_{5}^{+}$product ions derived from a specific $\mathrm{C}_{n}^{-+}$are a mixture of isomers which very likely arise by hydrogen migrations. Nevertheless, the odd/even alternation is also observed for the reactions of $\mathrm{C}_{n}^{\cdot+}$ with chloropropenes, and thus is clearly a second typical property of monocyclic carbon cluster ions.

A third effect which is probably characteristic of the ion/molecule reactions of monocyclic carbon cluster radical cations becomes apparent by the unexpected increased reactivity towards CP. A preferred reaction with $\mathrm{AC}$ by cleavage of the weak allylic $\mathrm{C}-\mathrm{Cl}$ bond is expected on thermodynamic grounds. We suggest that this chemoselectivity of the monocyclic $\mathrm{C}_{n}^{\cdot+}$ between the isomers of chloropropenes is due to the lower IE of CP. A general preference of $\mathrm{C}_{n}^{\cdot+}$ for organic substrates of low IE would be an interesting phenomenon and would help to understand the mechanism of carbon cluster growth. Thus, further experiments are under way in our laboratory for a more detailed study of this effect.

\section{Acknowledgment}

This research was supported by a grant from G.I.F., the German-Israeli Foundation for Scientific Research and Development. H.-F.G. wishes to thank the Deutsche Forschungsgemeinschaft for the gift of the FT-ICR mass spectrometer used for this research.

\section{References}

[1] For reviews see:

(a) W. Weltner, Jr. and R.J. Van Zee, Chem. Rev., 89 (1989) 1713.

(b) H. Schwartz, Angew. Chem., 104 (1991) 301. Angew. Chem. Int. Ed. Engl., 31 (1991) 183.

(c) Several articles in Acc. Chem. Res., 25, No. 3 (1992).

[2] (a) S.W. McElvany, J. Chem. Phys., 89 (1988) 2063;

(b) S.W. McElvany, B.I. Dunlap and A. O'Keefe, J. Chem. Phys., 86 (1987) 715.

[3] D.K. Bohme, S. Wlodek, L. Williams, L. Forte and A. Fox, J. Chem. Phys., 87 (1987) 6934.

[4] (a) R.J. Van Zee, R.F. Ferante, K.J. Zeringue and W. Weltner, Jr, J. Chem. Phys., 88 (1988) 3465.

(b) K. Raghavachari and J.S. Binkley, J. Chem. Phys., 87 (1987) 2191.

(c) V. Parasuk, J. Almlöf and M.W. Feyereisen, J. Am. Chem. Soc., 113 (1991) 1049.

(d) J. Bernholc and J.C. Phillips, Phys. Rev., B. 33 (1986) 7395 .

[5] (a) G. von Helden, M.-T. Hsu, P.R. Kemper and M.T. Bowers, J. Chem. Phys., 95 (1991) 3835;

(b) G. von Helden, N.G. Gotts and M.T. Bowers, J. Am. Chem. Soc., 115 (1993) 4363.

[6] R.C. Dunbar and B. Pozniak, presented at the Second European Workshop on FT-ICR Spectrometry, Antwerp, Belgium, September 7-9, 1993. 
[7] (a) J.A. Zimmerman and W.R. Creasy, J. Chem. Phys., 96 (1992) 1942 ;

(b) 95 (1991) 3267 .

[8] J. Sun, H.-Fr. Grützmacher and C. Lifshitz, J. Am. Chem. Soc., 115 (1993) 8382.

[9] J. Sun, H.-F. Grützmacher and C. Lifshitz, J. Phys. Chem., 98 (1994) 4536.

[10] D.C. Parent and S.W. McElvany, J. Am. Chem. Soc., 111 (1989) 2393.

[11] S.B.H. Bach and J.R. Eyler, J. Chem. Phys., 92 (1990) 358.

[12] P. Kofel, M. Allemann, Hp. Kellerhals and K.P. Wanczek, Int. J. Mass Spectrom. Ion Processes 65 (1985) 97.
[13] M. Alleman, Hp. Kellerhals and K.P. Wanczek, Int. J. Mass Spectrom. Ion Phys., 46 (1993) 139.

[14] M.T. Bowers, personal communication, 1994.

[15] R.G. Bergman, Acc. Chem. Res., 6 (1973) 25.

[16] T.H. Lowry and K. Schueller Richardson, Mechanism and Theory in Organic Chemistry, 3rd Edn., Harper, 1987.

[17] S.G. Lias, J.F. Liebman, R.D. Levin, S.A. Kafafi and S.E. Stein, NIST Standard Reference Data Base 25, (Vers. 2.01), 1994.

[18] B.F. Yates, W.J. Bouma and L. Radom, J. Am. Chem. Soc., 106 (1984) 5805.

[19] K.M. Stirk, L.K.M. Kiminkinen and H.I. Kenttämaa, Chem. Rev., 92 (1992) 1649. 